\title{
MULTIMEDIA VS CONCRETE MODEL: REVIEW OF STUDIES EMPLOYING THE TOOLS IN CHEMISTRY TEACHING
}

\author{
Rooserina Kusumaningdyah, Habiddin Habiddin*, Yudhi Utomo \\ Department of Chemistry, Faculty of Mathematics and Natural Sciences, Universitas Negeri Malang \\ Jl. Semarang No. 5 Malang, Indonesia
}

\begin{abstract}
This paper describes previous studies regarding the use of multimedia or virtual model and concrete model to improve students' understanding of chemistry. Thirty-three relevant papers in various topics, including stereochemistry, symmetry, chemical bonding, law conservation of matter, and others, were found and discussed. In particular, relevant studies in stereochemistry teaching is also discussed.
\end{abstract}

Keywords: Multimedia, Concrete Model, spatial ability, 3D orientation, stereochemistry

\section{INTRODUCTION}

Representation or manipulatives tools are among the most important technologies for learning at many levels. It is considered that manipulative tools can assist students in perceiving, understanding, and manipulating three-dimensional spatial relationships. For this reason, many education researchers have give a lot of effort into the refinement, development, and implementation of such tools (Stieff et al., 2005). Manipulative tools are widespread in many chemistry topics, particularly visuospatial aspects and space orientation such as stereochemistry, symmetry, and other relevant topics.

Manipulative models can be used to assist students in understanding abstract concepts and as instructional tools during learning. Several researchers, including Dayame (2019), suggest that this manipulative model can significantly improve student learning outcomes. Several manipulative models include hand-held, concrete, and multimedia models such as computer simulations (Kirk, 2015). The manipulatives tools are essential in enhancing students to achieve good performance in stereochemistry (Stull et al., 2012; Stieff et al., 2016; Knowles, 2017).

Today, efforts to improve the quality of technology-driven learning have attracted the interest of educators and the wider community. One of the interesting features of the technology is the application of multimedia. A multimedia tool or material can combine several elements in one package, namely text, images, animation, video, interactivity, and others. Multimedia can now improve learning outcomes (Chen \& Catramchenbone, 2014). Several chemistry learning experts have innovated to develop learning multimedia, including Sentongo et al. (2013), Chen et al. (2013), and Lou \& Lin (2012), and specializing in stereochemistry: da Silva et al. (2017), Harrold (1995), and SeviNç (2010). In many circumstances, the virtual laboratory has been employed in laboratory chemistry (Hakim et al., 2020; Muchson et al., 2019).

The developed learning multimedia is designed to display chemical material supported by multi-concept representations in two-dimensional visualization, three-dimensional virtual models presented in molecular modelling programs and animations in videos and games. For example,

${ }^{*}$ Corresponding author: Department of Chemistry, Faculty of Mathematics and Natural Sciences, Universitas Negeri Malang. Jl. Semarang No. 5 Malang, Indonesia. Email: Habiddin_wuni@um.ac.id 
multimedia is designed to illustrate difficult concepts such as chemical equilibrium. Concrete models have the advantage that students can physically interact with the models and see them in three dimensions. The advantages of virtual or multimedia media are that the bond length, bond angle, and valence are unlimited and manipulated. In addition, the advantages of virtual/multimedia models are that they are more cost-effective and do not require much time to construct other molecular models (O’Brien, 2016).

\section{METHOD}

This study employed a literature review of multimedia and concrete model articles. The literature review discussed previous research on multimedia and concrete model effectiveness in chemistry teaching and beyond. The details of the articles studied are provided in Table 1.

Table 1. Reviewed Articles

\begin{tabular}{|c|c|c|c|}
\hline No. & Authors (Year) & Notes & Publication \\
\hline 1. & Anggriawan (2017) & Multimedia and students' understanding of symmetry & Master thesis \\
\hline 2. & Beauchamp (1984) & $\begin{array}{l}\text { Bodyparts (arm and fingers) and chiral centres: } \\
\text { stereochemistry }\end{array}$ & International journal \\
\hline 3. & Chen et al. (2013) & Multimedia technology in a chemistry laboratory & International journal \\
\hline 4. & $\begin{array}{l}\text { Chen \& Catrambone } \\
(2014)\end{array}$ & Multimedia Interactivity and spatial ability & International journal \\
\hline 5. & Da Silva et al. (2017) & Computer game and understanding of stereochemistry & International journal \\
\hline 6. & Dori \& Barak (2001) & $\begin{array}{l}\text { Virtual and Physical model: Understanding of organic } \\
\text { chemistry, Model Perception and Spatial Understanding. }\end{array}$ & International journal \\
\hline 7. & Harrold (1995) & Molecular modelling \& stereochemistry & International journal \\
\hline 8. & Hakim et al. (2020) & Virtual vs real laboratory & $\begin{array}{l}\text { National accredited } \\
\text { journal }\end{array}$ \\
\hline 9. & Thayban et al. (2021) & Virtual and concrete model in chemistry teaching: review & $\begin{array}{l}\text { National accredited } \\
\text { journal }\end{array}$ \\
\hline 10. & Thayban et al. (2021) & Virtual and concrete model \& understanding of symmetry & International journal \\
\hline 10. & Kirk (2015) & $\begin{array}{l}\text { Manipulatives Tool \& Understanding of the Law of } \\
\text { Conversation of Matter }\end{array}$ & Master Thesis \\
\hline 11. & Knowles (2017) & Eye-Tracking and Molecular Modelling & PhD Thesis \\
\hline 12. & Koutalas et al. (2014) & 2D Molecular model \& spatial ability & $\begin{array}{l}\text { International } \\
\text { proceeding }\end{array}$ \\
\hline 13. & Lou \& Lin (2012) & Multimedia & International journal \\
\hline 14. & O’Brien, M. (2016) & 3-D \& Stereoselective Reaction Pathways & International journal \\
\hline 15. & Olimpo et al(2015) & 2D \& Translation ability & International journal \\
\hline 16. & Sentongo et al. (2013) & Computer Simulations \& Chemical Bonding & International journal \\
\hline 17. & Sevï (2010) & Computer Simulations \& Chemical Bonding & Conference proceeding \\
\hline 18. & Stieff et al. (2005) & Visualization tool & Book chapter \\
\hline 19. & Stieff et al (2016) & Concrete Model \& Representational Competence & International journal \\
\hline 20. & Stull et al. (2013) & Concrete and Virtual Models & International journal \\
\hline 21. & Stull et al (2012) & Concrete model \& representational Translation & International journal \\
\hline
\end{tabular}


The articles were selected based on matching with "concrete model, virtual model, spatial ability, virtual model" keywords. All of the terminologies covers the area of models and modelling in chemistry. Some related articles in the non-chemistry area were also found searching the articles. However, we limited our review to chemistry-related teaching only for avoiding excessive work.

\section{RESULTS AND DISCUSSION}

As presented in Table 1, the use of virtual models and concrete models in chemistry teaching have been popular and published in many international journals and international proceedings. However, those published in national accredited journals are limited. In national accredited journals, we found an article reviewing the role of concrete and virtual models in students' chemistry understanding (Thayban et al., 2020). We realize that the procedure applied in this review may not cover all the relevant studies published in Indonesian accredited journals. Therefore, it will sound too ambitious to build a general claim. However, this may indicate that such study in this area is still not widely explored in Indonesia.

Studies regarding virtual and concrete models have been well known internationally. Such studies have been published in many journals and international proceedings, including highly reputable journals such as science education, chemistry education research and practice and journal of chemical education. Thayban et al. (2021) described the role of virtual and concrete models in symmetry teaching and revealed that the virtual model demonstrated a higher contribution than the concrete model. 2D representation influenced students' success in translating from one representation to another in organic chemistry courses (Olimpo et al., 2015). This fact indicates that a novel, up-to-date, and progressive approach should be employed for similar studies to be accepted in reputable journals.

The use of concrete models has been done for a long time. In the 1940s, Pitzer and Hazel won the Nobel Prize in chemistry for demonstrating the axial and equatorial forms of the seat conformation of the cyclohexane ring using a concrete model. Molecular models such as spacefilling 30 years later became an indispensable tool because they can help predict conformational structure, stereochemistry, reactivity and physical properties in organic chemistry (Dori et al., 1999). Sachse, one of the chemists, also uses molecular models to predict the shape of the "boat" and "chair" conformation of cyclohexane. A study was also conducted by Boukhechem et al. (2016) to determine to what extent concrete models or molymods can develop students' abilities in translating and coordinating between 2D to 3D representations and vice versa in Stereochemical topics. Examples of the representation are the Newman projection, the Fischer projection, and the dimensional formula, as shown in Figure 1.

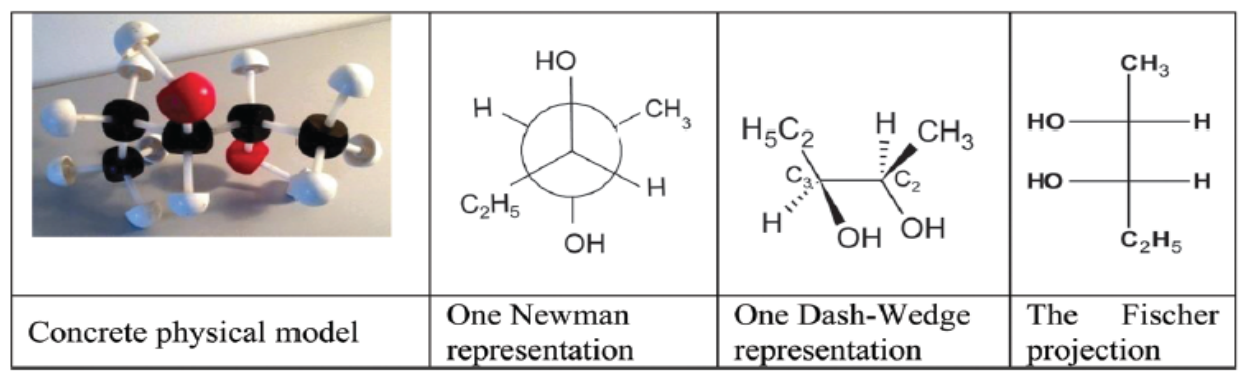

Figure 1. Some forms of Stereochemical Representation (Source: Boukhechem, 2016)

These stereochemical representations require students to construct, identify, interpret, and coordinate the differences between these representations (Stull et al., 2012). Raje and Stieff also stated that students with weak reasoning skills would find it difficult to identify the correlation 
between conformational differences and the energy differences of each conformation molecule (Stieff et al., 2016).

Concrete models have the advantage that students can physically interact with these models and see them in three-dimensional form (O'Brien, 2016). Real models can also visualize the transition state of stereoselective or diastereoselective reaction mechanisms. To a certain extent, using real models with this approach is more difficult because the molecules need to be held in place by hand. This means that overlay drawing cannot be done simultaneously and necessitates recording a video of the manipulation first, then creating a new one with the annotation added. This could be alleviated if some clamping mechanism was used to hold the model steady whilst the overlaid line diagram was drawn.
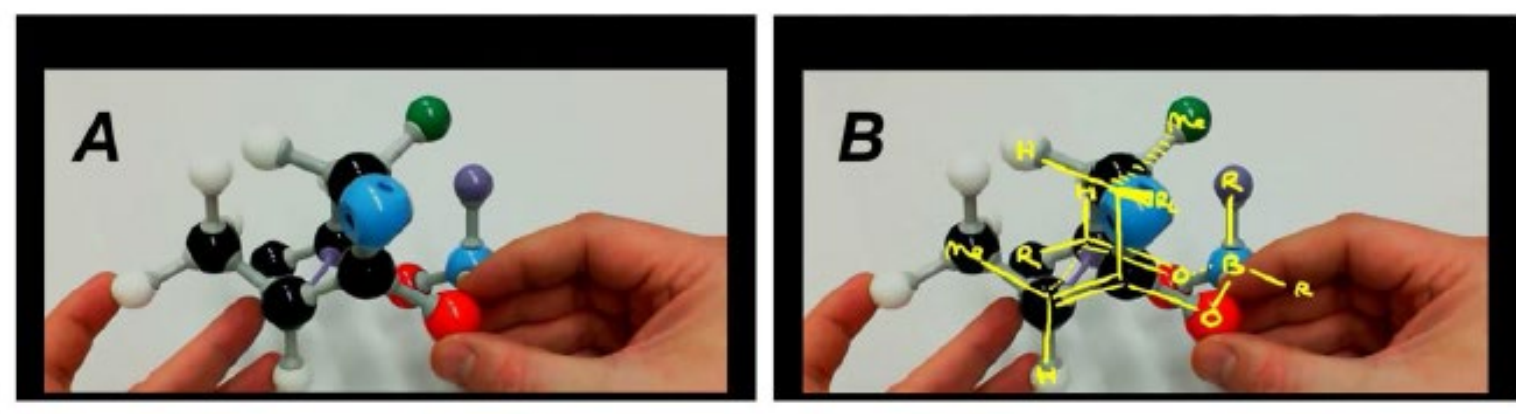

Figure 2. Use of physical models (Molymod). A) Transition-state structure made with Molymod system manipulated, using a webcam to make a video. B) Video played and paused to show a particular viewpoint. (Source: O’Brien, 2016)

\section{Relative Effectiveness of Multimedia and Concrete Model on Enhancing Conceptual Understanding in Stereochemistry}

Many studies have been carried out to compare the relative effectiveness of multimedia and concrete models. However, the finding result shows that some studies revealed that multimedia had outperformed the concrete model. On the other hand, several studies also found that the concrete model is more appropriate to be implemented on a typical certain learning process. Olkun (2003) stated that both computer and concrete positively affect students' geometric reasoning about two-dimensional geometric shapes, especially on spatial tasks. Although the positive trend is obvious and the computer group gained relatively more from the intervention than the concrete group, the overall difference between the experimental groups (concrete versus computer) was not statistically significant.

Therefore, the choice between computer versus concrete manipulatives is not very clear. Both computer and concrete positively affect students' geometric reasoning about twodimensional geometric shapes, especially on spatial tasks. Although the positive trend is obvious and the computer group gained relatively more from the intervention than the concrete group, the overall difference between the experimental groups (concrete versus computer) was not statistically significant. Meanwhile, Dori \& Barak (2001) promoted multimedia and concrete media during the learning process in chemistry. It is objected that multimedia can overcome the limitless of the concrete model and vice versa, so both of them complement each other.

It was also revealed that the accuracy for both model types was high and did not differ between the two model types, multimedia and concrete model. This suggests that multimedia models can offer the same benefits for teaching chemistry instructions as concrete models. More importantly, because they are digital, they can be delivered to more people and more rapidly across the internet and ubiquitous technologies such as smartphones tablets. In addition, they can be integrated more easily into e-learning resources such as online learning, ebooks, digital tutorial systems, customized to service individual needs, and programmed to behave in task beneficial 
ways (Stull et al., 2013). So it is related that multimedia has more beneficial than concrete media based on its availability, efficiency and flexibility.

O'Brien (2016) also asserts that molecular models, either real or virtual, are extremely useful in aiding students' understanding of stereochemical concepts. The study reveals that multimedia or virtual model has an advantage. The bond lengths, bond-angles and valencies are not restricted in any way. In addition, virtual models are essentially free, assuming free access to a computer, and take no time to re-construct, thus allowing students to swap between several models easily. Furthermore, Abraham and colleagues (Knowles, 2017) also conducted research exploring the relative effectiveness of several kinds of molecular representation on students' understanding of stereochemistry concepts. The resulting study indicates that multimedia or virtual media was the most effective representation type. Nevertheless, the physical model or handled model can also help students learn difficult stereochemistry concepts, and for most, organic chemistry classrooms have no access to computer visualization software.

Meanwhile, Stull et al. (2012) also added several advantages of physical models. One of these advantages is that a physical model can represent the three-dimensional structure externally and give an accurate performance. For example, when doing the rotating task for depicting the 3$\mathrm{D}$ structure of the molecule in the two dimensions. A physical rotation of a model is holistic. Because the model is rigid, it maintains the spatial relations between its components when the whole model is rotated, which can not be demanding on working memory.

\section{CONCLUSION}

Our review found that studies employing concrete and virtual models in chemistry teaching may not be very popular in Indonesia except in international areas. The number of relevant studies found in Indonesian journals is limited, but many for international journals. This phenomenon indicates that such a study has been well known internationally. Therefore, to get accepted in an international journal for this study, a progressive approach may be added. However, we realize that this review may sound too ambitious to claim that this result represents the fact. A more comprehensive review involving wider chemistry and science education journals will be further carried out.

\section{REFERENCES}

Anggriawan, B. (2017). Pengarub Pembelajaran Penemuan Terbimbing Berbantuan Multimedia terbadap Pemahaman Materi Simetri Mahasiswa dengan Kemampuan Spasial yang Berbeda. Universitas Negeri Malang.

Beauchamp, P. S. (1984). "Absolutely" Simple Stereochemistry. Journal of Chemical Education, 61(8), 666. https://doi.org/10.1021/ed061p666

Boukhechem, M.-S., Dumon, A., \& Zouikri, M. (2011). The Acquisition of Stereochemical Knowledge by Algerian Students Intending to Teach Physical Sciences. Chemical Education Research and Practise, 12(3), 331-343. https://doi.org/10.1039/C1RP90040D

Chen, D., Chen, X., \& Gao, W. (2013). The Application and Perspective of Multimedia Technology in Chemistry Experimental Instruction in China. Creative Education, 04(04), 241-247. https://doi.org/10.4236/ce.2013.44035

Chen, D.-W., \& Catrambone, R. (2014). Effects of Multimedia Interactivity on Spatial Task Learning Outcomes. Proceedings of the Human Factors and Ergonomics Society Annual Meeting, 58(1), 1356-1360. https://doi.org/10.1177/1541931214581283

da Silva Júnior, J. N., Sousa Lima, M. A., Xerez Moreira, J. V., Oliveira Alexandre, F. S., de Almeida, D. M., de Oliveira, M. da C. F., \& Melo Leite Junior, A. J. (2017). Stereogame: An Interactive Computer Game That Engages Students in Reviewing Stereochemistry 
Concepts. Journal of Chemical Education, 94(2), 248-250.

https://doi.org/10.1021/acs.jchemed.6b00475

Dayame, A. M. (2019). The Effects of Manipulative and Visual Models in Conceptualizing Fractions. International Journal of Advanced Research and Publications, 3(8), 80-85.

Dori, Y. J., \& Barak, M. (2001). Virtual and Physical Molecular Modeling: Fostering Model Perception and Spatial Understanding. Educational Technology \& Society, 4(1), 61-74.

Hakim, M. F., Maksum, A. H., Saragih, Y., \& Hasanah, C. S. (2020). Analysis on the implementation of virtual versus reality laboratory. J-PEK (Jurnal Pembelajaran Kimia), 5(2), 59-65. https://doi.org/10.17977/UM026V5I22020P059

Harrold, M. W. (1995). Computer-Based Exercises to Supplement the Teaching of Stereochemical Aspects of Drug Action1,2. American Journal of Pharmaceutical Education, 59, $20-26$.

Kirk, J. (2015). Using Manipulatives in The Chemisty Classroom as a Tool to Increase The Understanding and Knowledge of The Law of Conversation of Matter. St. John Fisher College: Fisher Digital Publications:

Knowles, T. H. (2017). Using Eye-Tracking and Molecular Modelling to Explore Students' Strategies for Solving Organic Stereochemical Problems. University of Northern Colorado.

Koutalas, V. G., Antonoglou, L. D., Charistos, N. D., \& Sigalas, M. P. (2014). Investigation of Students' Ability to Transform and Translate 2D Molecular Diagrammatic

Representations and its Relationship to Spatial Ability and Prior Chemistry Knowledge. Procedia - Social and Behavioral Sciences, 152, 698-703. https://doi.org/10.1016/j.sbspro.2014.09.265

Lou, S.-J., \& Lin, H.-C. (2012). Improving the Effectiveness of Organic Chemistry Experiments through Multimedia Teaching Materials for Junior High School Students. The Turkish Online Journal of Educational Technology, 11(2), 135-141.

Muchson, M., Munzil, M., Winarni, B. E., \& Agusningtyas, D. (2019). Pengembangan virtual lab berbasis android pada materi asam basa untuk siswa SMA. J-PEK (Jurnal Pembelajaran Kimia), 4(1), 51-65. https://doi.org/10.17977/UM026V4I12019P051

O’Brien, M. (2016). Creating 3-Dimensional Molecular Models to Help Students Visualize Stereoselective Reaction Pathways. Journal of Chemical Education, 93(9), 1663-1666. https://doi.org/10.1021/acs.jchemed.6b00250

Olimpo, J. T., Kumi, B. C., Wroblewski, R., \& Dixon, B. L. (2015). Examining The Relationship Between 2D Diagrammatic Conventions and Students' Success on Representational Translation Tasks in Organic Chemistry. Chemistry Education Research and Practice, 16(1), 143-153. https://doi.org/10.1039/C4RP00169A

Olkun, S. (2003). Comparing Computer versus Concrete Manipulatives in Learning 2D Geometry. Journal of Computers in Mathematics and Science Teaching, 22(1), 43-56. https://doi.org/10.1501/0000984

Sentongo, J., Kyakulaga, R., \& Kibirige, I. (2013). The Effect of Using Computer Simulations in Teaching Chemical Bonding: Experiences with Ugandan Learners. International Journal of Education Science, 5(4), 433-441.

SeviNç, B. (2010). The Effect Of Computer Based Instruction Enhanced With Concept Maps On Students' Understanding Of Stereochemistry. International Conference on New Trends in Education and Their Implications, 301-306.

Stieff, M., Bateman, R. C., \& Uttal, D. H. (2005). Teaching and Learning with Three-dimensional Representations. In J. K. Gilbert (Ed.), Visualization in Science Education (pp. 93-120). Springer Netherlands. https://doi.org/10.1007/1-4020-3613-2_7

Stieff, M., Scopelitis, S., Lira, M. E., \& Desutter, D. (2016). Improving Representational Competence with Concrete Models. Science Education, 100(2), 344-363. https://doi.org/10.1002/sce.21203 
Stull, A. T., Barrett, T., \& Hegarty, M. (2013). Usability of Concrete and Virtual Models in Chemistry Instruction. Computers in Human Behavior, 29(6), 2546-2556. https://doi.org/10.1016/j.chb.2013.06.012

Stull, A. T., Hegarty, M., Dixon, B., \& Stieff, M. (2012). Representational Translation With Concrete Models in Organic Chemistry. Cognition and Instruction, 30(4), 404-434. https://doi.org/10.1080/07370008.2012.719956

Thayban, T., Habiddin, H., \& Utomo, Y. (2020). Concrete Model VS Virtual Model: Roles and Implications in Chemistry Learning. J-PEK (Jurnal Pembelajaran Kimia), 5(2), 90-107. https://doi.org/10.17977/UM026V5I22020P090

Thayban, T., Habiddin, H., Utomo, Y., \& Muarifin, M. (2021). Understanding of Symmetry: Measuring the Contribution of Virtual and Concrete Models for Students with Different Spatial Abilities. Acta Chimica Slovenica, 68(3). https://doi.org/10.17344/acsi.2021.6836 